\title{
Bilateral Plexiform Neurofibromatosis Involving Brachial Plexus and Lumbosacral Plexus
}

\author{
Anshu Chandrakant Warade ${ }^{1}$ Ketan I. Desai ${ }^{1}$ \\ ${ }^{1}$ Department of Neurosurgery, P. D. Hinduja Hospital, Mumbai, \\ Maharashtra, India
}

Indian J Neurosurg:2020;9:233-235

\begin{abstract}
Address for correspondence Anshu Chandrakant Warade, DNB, Department of Neurosurgery, P. D. Hinduja Hospital, Veer Sawarkar Marg, Mahim, Mumbai 400016, Maharashtra, India (e-mail: dranshuwarade@gmail.com).
\end{abstract}

\begin{abstract}
Plexiform neurofibroma is a common feature in patients of neurofibromatosis 1 . It

Keywords

- neurofibromatosis

- plexiform

- bilateral tends to infiltrate and separate the normal fascicles. Surgery is offered only when there is neurological deficit or intractable pain. We present a rare case of a 22 -year-old female with bilateral neurofibromatosis involving brachial plexus, lumbosacral plexus, and sciatic nerves.
\end{abstract}

both sciatic nerves by multiple neurofibromas in gluteal and thigh regions.

$\mathrm{PN}$ is a common entity associated with neurofibromatosis 1. It occurs in multiple numbers as twisted masses and grow along the axis of the nerve. Its growth pattern is infiltrating and separating normal nerve fascicles. Malignant transformation is the known associated complication. Surgery is only indicated when PNs start causing functional compromise, deformity, or intractable pain. ${ }^{1 .}$ Only two cases have been reported so far in the literature, as observed in our patient (-Figs. 1-3). . $^{2,3}$
DOI https://doi.org/

$10.1055 / \mathrm{s}-0040-1714168$

ISSN 2277-954X. (c) 2020. Neurological Surgeons' Society of India.

This is an open access article published by Thieme under the terms of the Creative Commons Attribution-NonDerivative-NonCommercial-License, permitting copying and reproduction so long as the original work is given appropriate credit. Contents may not be used for commercial purposes, or adapted, remixed, transformed or built upon. (https://creativecommons.org/licenses/by-nc-nd/4.0/)

Thieme Medical and Scientific Publishers Pvt. Ltd., A-12, 2nd Floor, Sector 2, Noida-201301 UP, India 


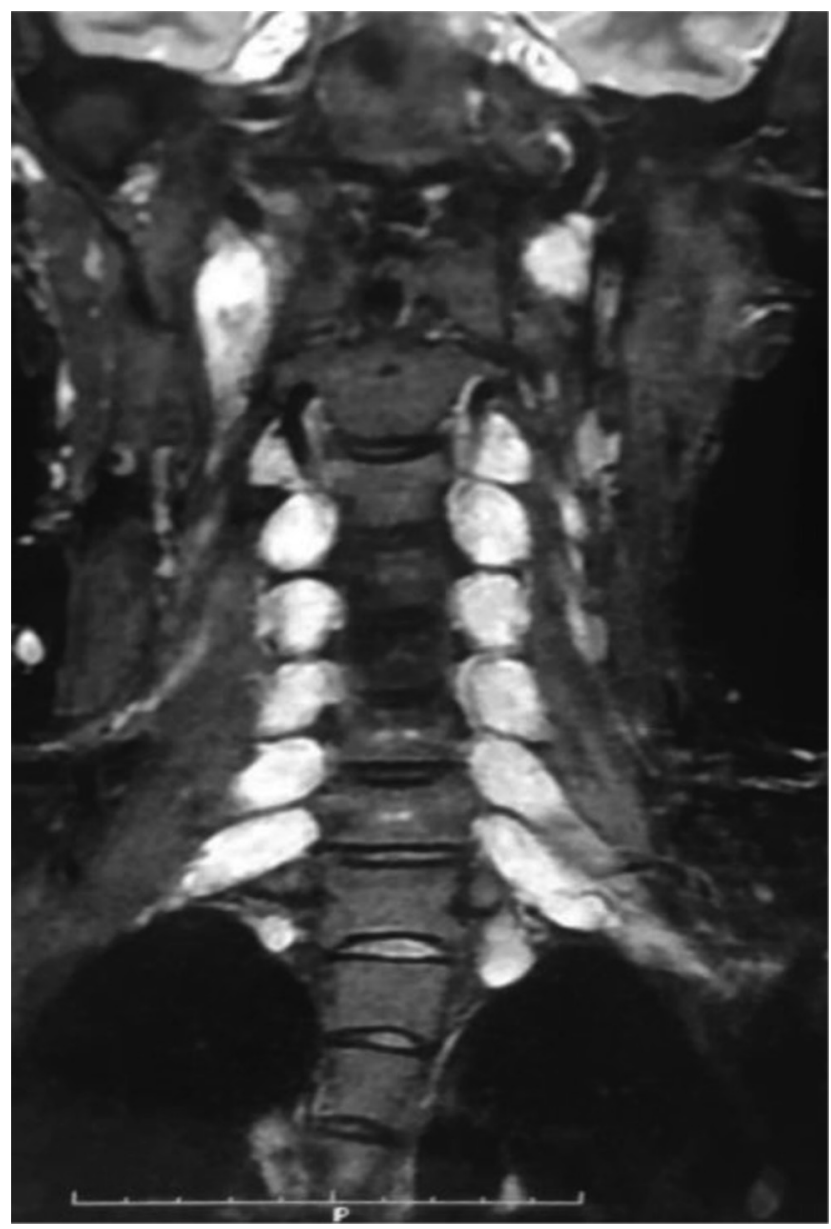

Fig. 1 Short tau inversion recovery coronal magnetic resonance imaging of brachial plexus showing multiple neurofibromas along bilateral roots of brachial plexu.

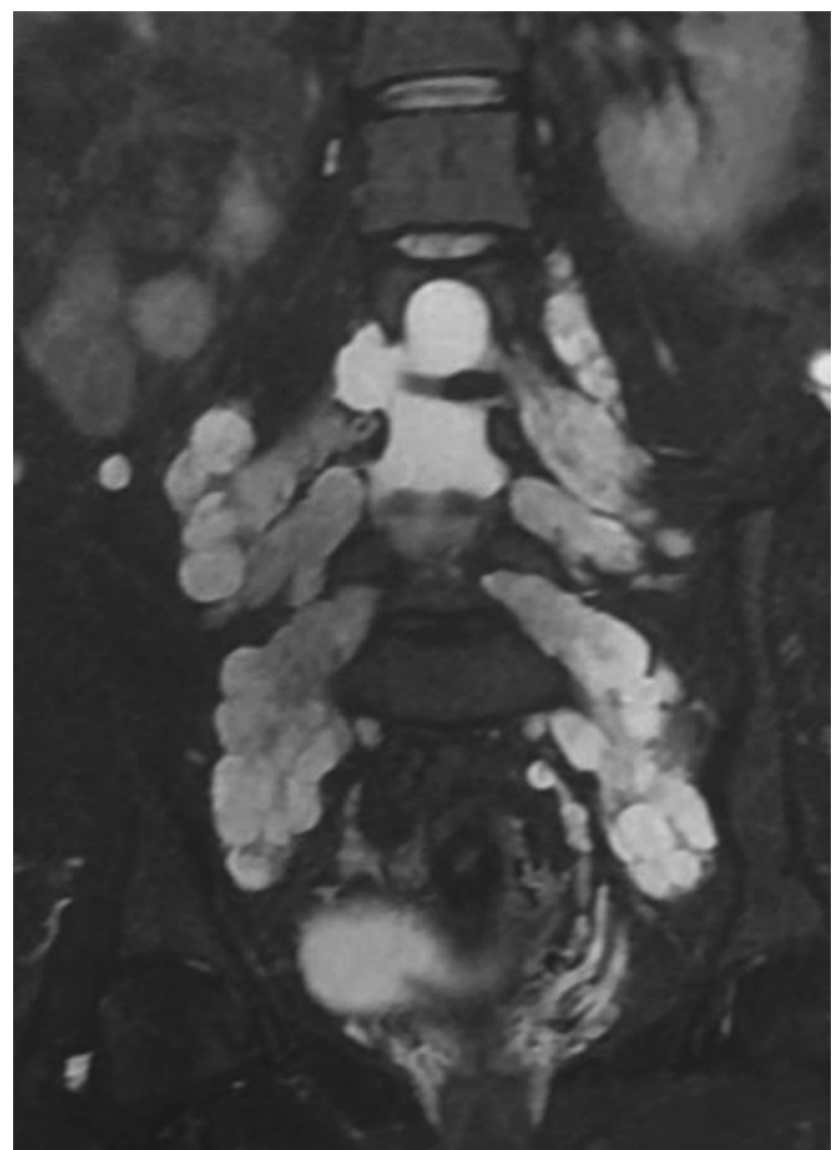

Fig. 2 Short tau inversion recovery coronal magnetic resonance imaging of lumbosacral plexus showing multiple plexiform neurofibromas along lumbosacral roots. 


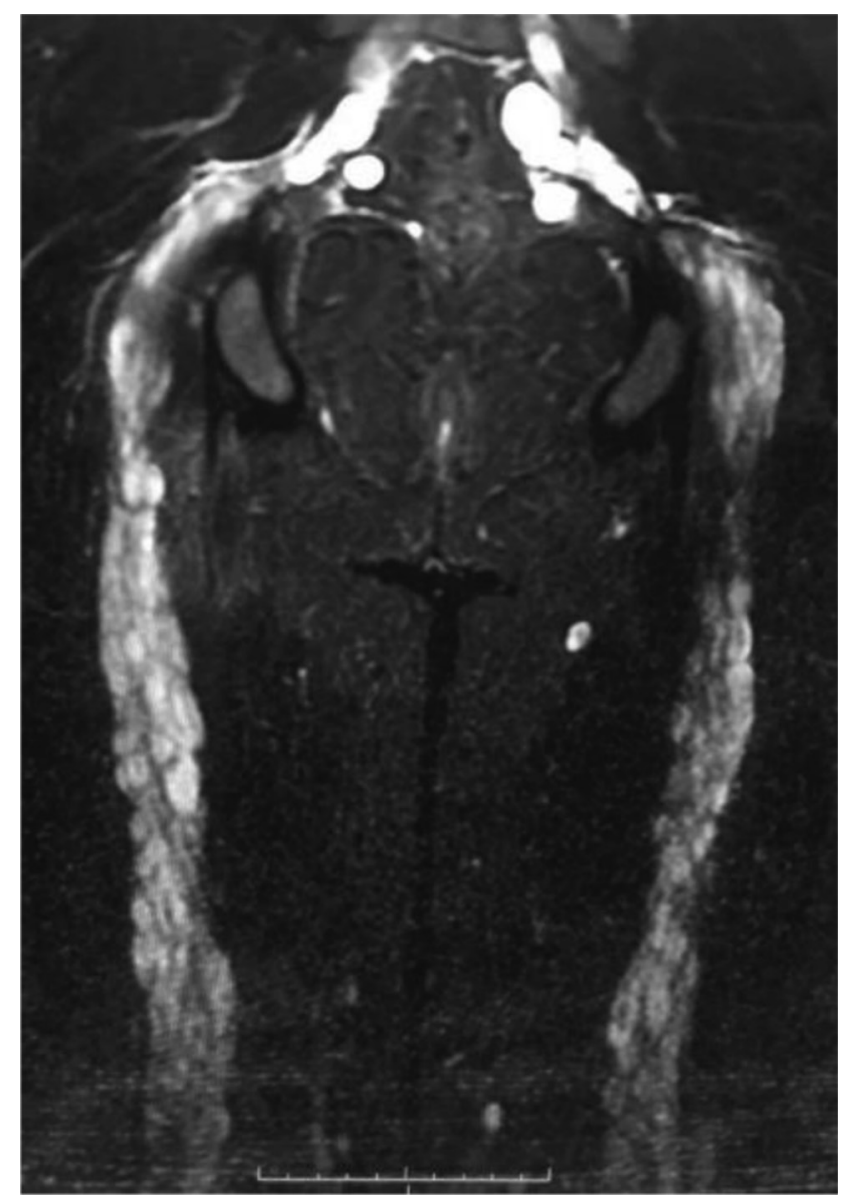

Fig. 3 Short tau inversion recovery coronal magnetic resonance imaging of thigh showing multiple plexiform neurofibromas along bilateral sciatic nerves.

\section{Conflict of Interest}

None declared.

\section{References}

1 Serletis D, Parkin P, Bouffet E, Shroff M, Drake JM, Rutka JT. Massive plexiform neurofibromas in childhood: natural history and management issues. J Neurosurg 2007;106(5, Suppl): 363-367

2 Kumar A, Devi BI. Enigma in management of plexiform neurofibromas of bilateral brachial and lumbosacral plexuses: shall we let nature take its course. ?Neurol India 2019; 67(Suppl):S154-S156

3 Souza FH, Dabdoub CB, Bernardino SN, Silveira EN, Litvin S, Azevedo-Filho $\mathrm{H}$. Bilateral plexiform neurofibromas of the brachial and lumbosacral plexuses. Arq Neuropsiquiatr 2013; 71(2):128-130 